\title{
VARSTVO GEOGRAFSKEGA OKOLJA V DOBI GLOBALIZACIJE- SLOVENIJA IN AGENDA 21
}

\author{
Dušan Plut*
}

\section{Izvleček}

Slovenija je na svetovni konferenci o okolju in razvoju leta 1992 v Rio de Janeiru podpisala Agendo 21, ki predvideva okrepitev sonaravnih, okolju prilagojenih dejavnosti. Ocena uresničevanja načel Agende 21 po letu 1992 v Sloveniji je bila izvedena $s$ pomočjo primerjave vrednosti okoljskih kazalcev za zmanjševanje nekaterih zračnih emisij, zaščite gozda, biotske raznovrstnosti in sveže vode. Slovenija večino okoljskih ciljev Agende 21 še ne uresničuje v zadovoljivi meri.

Ključne besede: Agenda 21, Slovenija, okoljski kazalci, sonaravni razvoj

\section{PROTECTION OF GEOGRAPHIC ENVIRONMENT IN THE PERIOD OF GLOBALIZATION - SLOVENIA AND AGENDA 21}

\begin{abstract}
Slovenia has on the world conference on environment and development, held in year 1992 in Rio de Janeiro, signed Agenda 21 which foresees strengthening of sustainable, to the environment adapted activities. Estimation of realization of the stipulations of Agenda 21 after year 1992 in Slovenia was executed on the basis of comparison of values of environmental indicators for decrease of some air emissions, forest protection, biotic variety and fresh water. Slovenia is not executing most of environmental aims of Agenda 21 to the satisfactory extent.
\end{abstract}

Key words: Agenda 21, Slovenia, environmental indicators, sustainable development

\footnotetext{
${ }^{*}$ Dr. izred. prof., Oddelek za geografijo, Filozofska fakulteta Univerze v Ljubljani, Aškerčeva 2, SI 1000 Ljubljana, Slovenija
} 


\section{ODZIVI NA GLOBALIZACIJO VARSTVA OKOLJA}

Agenda 21 (1992) svetovne konference o okolju in razvoju v Rio de Janeiru pomeni kljub akcijski in finančni nedorečenosti začetek globalnih prizadevanj za iskanje novih poti materialno zmerne, socialno pravične in okolju prilagojene prihodnosti za vse prebivalce planeta. Agendo 21, svetovni razvojno okoljski civilizacijski načrt, je v Riu junija 1992 podpisalo 178 držav, med njimi tudi Slovenija. To torej pomeni, da želi Slovenija gospodarski napredek graditi hkrati z izboljšanjem stanja planetarnega ekosistema in geografskega okolja na lastnem ozemlju. V dobi globalizacije, čezmejnega onesnaževanja in prekomerne rabe domačih ali uvoženih naravnih virov je torej neobhodno zmanjševanje okoljskih pritiskov in izboljšanje kakovosti geografskega okolja na ozemlju države brez hkratnega povečanja obremenjevanja ekosistema planeta.

\section{SLOVENIJA IN URESNIČEVANJE NEKATERIH OKOLJSKIH CILJEV AGENDE 21}

S pomočjo nekaterih karakterističnih okoljskih kazalcev sonaravnega razvoja poskušali ugotoviti ali Slovenija po podpisu Rio deklaracije sledi temeljnim okoljskim ciljem Agende 21, zlasti na tistih poljih okoljskih pritiskov, ki pomembneje vplivajo tudi na delovanje in ravnovesje globalnega ekosistema (Preglednica 1). Tako bomo poskušali ugotoviti ali je Slovenija glede varstva geografskega okolja in naravnih virov začela udejanjati načela in cilje Agende 21 (1992).

Preglednica 1: Izbrani okoljski kazalci Agende 21

\begin{tabular}{|c|c|c|c|}
\hline $\begin{array}{l}\text { Polje } \\
\text { Agende } 21\end{array}$ & $\begin{array}{l}\text { Kazalec gonilnih sil } \\
\text { onesnaževanja }\end{array}$ & Kazalec stanja okolja & Kazalec odziva \\
\hline $\begin{array}{l}\text { Zaščita } \\
\text { ozračja (9) }\end{array}$ & $\begin{array}{ll}\text { - } & \text { emisije plinov tople grede } \\
\text { - } & \text { emisije razkrojevalcev } \\
\text { ozona v stratosferi } \\
\text { - } & \text { emisije NOx }\end{array}$ & $\begin{array}{l}\text { - } \quad \begin{array}{l}\text { emisije na prebivalca } \\
\text { in površino } \\
\text { koncentracije zračnih } \\
\text { onesnaževalcev }\end{array} \\
\end{array}$ & $\begin{array}{ll}\text { - } & \text { trendi } \\
\text { emisij }\end{array}$ \\
\hline $\begin{array}{l}\text { Zmanjševanje } \\
\text { krčenja } \\
\text { gozda (11) }\end{array}$ & - $\quad$ intenzivnost poseka lesa & $\begin{array}{l}\text { - } \quad \text { sprememba gozdnih } \\
\text { površin }\end{array}$ & 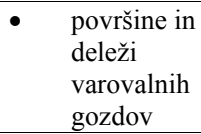 \\
\hline $\begin{array}{l}\text { Zaščita biotske } \\
\text { raznovrstnosti (15) }\end{array}$ & $\begin{array}{l}\text { - } \quad \text { zmanjševanje odprtega } \\
\text { prostora }\end{array}$ & $\begin{array}{l}\text { - } \quad \text { izumrle in ogrožene } \\
\text { vrste }\end{array}$ & 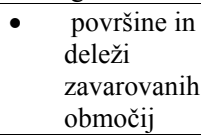 \\
\hline $\begin{array}{l}\text { Zaščita kakovosti } \\
\text { virov sveže vode in } \\
\text { oskrbe } z \text { vodo }(18)\end{array}$ & $\begin{array}{l}\text { - } \quad \text { poraba vode glede na } \\
\text { razpoložljive vodne vire }\end{array}$ & - $\quad$ kakovost vodnih virov & 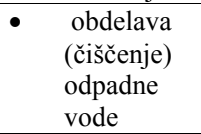 \\
\hline
\end{tabular}

Vir: Agenda 21; Indicator of Sustainable..., 1996; Indicator of Sustainable...1997 


\section{ZAŠČITA OZRAČJA (CILJ 9)}

\section{Zmanjševanje emisij plinov tople grede}

Po podatkih Ministstva za okolje so emisije $\mathrm{CO}_{2}$ leta 1995 znašale 14,7 milijona ton oziroma $7400 \mathrm{~kg}$ na prebivalca, leta 1996 pa 15,8 milijona ton oziroma $7900 \mathrm{~kg}$ na prebivalca ali 781,3 tone na $\mathrm{km}^{2}$ (Okolje v Sloveniji..., 1998). Glede na emisije $\mathrm{CO}_{2}$ iz fosilnih goriv, ki prispevajo največji delež k učinku tople grede, je bila Slovenija s $7900 \mathrm{~kg} \mathrm{CO} 2$ na prebivalca v letu 1996 nad svetovnim (okoli $4300 \mathrm{~kg} \mathrm{CO}$ na prebivalca) in vse bližje sicer visokemu povprečju držav EZ (okoli $9000 \mathrm{~kg}$ na prebivalca). Vendar je potrebno podčrtati, da so se skupne emisije $\mathrm{CO}_{2} \mathrm{~V}$ EZ v obdobju 1990-1996 stabilizirale oziroma zmanjšale za 0,7\%, hkrati pa se je BDP povečal za $9 \%$ (Environment in the..., 1999, s. 92). Slovenija je torej po podpisu Agende 21, tako kot velika večina drugih držav na svetu, emisije ogljikovega dioksida povečala.

Prav tako se se po letu 1992 ponovno začele povečavati emisije dušikovih oksidov, drugega plina tople grede (Okolje v Sloveniji..., 1998, s. 57). Leta 1995 so emisije NOx znašale 66600 ton, leta 1996 pa 70400 ton oziroma 35,4 kg na prebivalca. Delež cestnega prometa pri skupnih emisijah NOx je največji $(66 \%)$ in se hkrati povečuje. Letne količine metana so se v prvi polovici 90 . let nekoliko zmanjšale, še bolj pa emisije CFC-jev.

Skupne emisije plinov tople grede in slovenskih virov so se v letih po sprejetju Agende 21(1992-1996) povečale in so leta 1995 znašale približno 21 milijonov ton $\mathrm{v} \mathrm{CO}_{2}$ ekvivalentih oziroma 10,7 tone na prebivalca (Okolje v Sloveniji..., 1998, s. 286).

\section{Zmanjševanje emisij plinov, ki razkrajajo stratosferski ozon}

Naša država ne proizvaja, temveč uvaža in uporablja ozonu škodljive snovi. Slovenija je leta 1992 ratificirala Montrealski sporazum in t.i. Londonske dopolnitve, julija 1994 je vlada RS sprejela program opuščanja ozonu škodljivih snovi in v ta namen prejela 6,2 milijona dolarjev mednarodne pomoči.

Od ozonu škodljivih snovi so v Sloveniji najpomembnejši CFC, 1,1,1-trikloretan in HCFC. Poraba CFC je v obdobju 1986-1995 upadla in je leta 1995 bila $13 \%$ glede na leto 1986, dopustna raven porabe pa je $25 \%$ (Okolje v Sloveniji..., 1998, s. 285).

Tudi porabo drugih ozonu škodljivih snovi je v Sloveniji zniževala v skladu s sprejetimi mednarodnimi obveznostmi. Vendar strokovnjaki opozarjajo, da lahko začetek izboljšanja v stratosferski ozonski plasti pričakujemo šele okoli leta 2030, v naslednjih desetletjih pa se bo količna ultravijoličnega sevanja in posledice še povečevale (Environment in the..., 1999, s. 26). 


\section{PREPREČEVANJE ZMANJŠANJA GOZDNIH POVRŠIN (CILJ 11)}

\section{Zmanjševanje gozdnih površin}

Sredi devetdesetih let so strnjeni gozdovi planeta obsegali $24 \%$ manj površin kot leta 1700, oziroma 3,4 milijarde ha (brez grmovja in razredčenega gozda) v primerjavi s 4,5 milijarde ha pred 300 leti (Plut, 1998). Večina tega gozda je bila posekanega zaradi širjenja obdelovalnih površin, pa tudi pašnikov, sečnje in nabiranja drv, rasti mest in predmestij ter gradnje cest.

V obdobju 1970-1990 so se gozdne površine na svetu zmanjšale za 6 \% (Europe's Environment, 1995, s. 320). V zmernem pasu pa so se gozdne površine nekoliko povečale. V EZ pokrivajo gozdovi 97,6 milijonov ha, kar predstavlja $36 \%$ gozdnatost (Pogačnik, 1998, s. 98). Finska in Švedska imata skupaj kar $46 \%$ gozdov EZ ter hkrati največ gozda na prebivalca (Švedska - 2,85 ha, Finska - 4,03 ha). Primerjalni jima sledi Slovenija s 54 \% gozdnatostjo in 0,56 ha gozda na prebivalca. Normativ za zadovoljivo samooskrbo $\mathrm{z}$ lesom je 0,25 ha gozda na prebivalca, 0,12 ha njiv na prebivalca Slovenije pa predstavlja kritično mejo za zagotovitev prehranske samooskrbe (Kladnik, Gabrovec, 1998, s. 181). Vendar je potrebo hkrati poudariti, da prinaša povečevanje gozda tudi nekatere negativne okoljske posledice, zlasti naraščanje okoljskih pritiskov na skrčene kmetijske površine. $Z$ vidika sonaravnega razmerja med gozdnimi in negozdnimi površinami je v vzpetih območjih Slovenije verjetno delež gozdnih površin že dosegel ali v nekaterih hribovitih pokrajinah celo presegel zaželeni delež.

Lesna zaloga in prirastek slovenskih gozdov se stalno povečujeta. V letu 1990 je povprečna lesna zaloga znašala $192 \mathrm{~m}^{3} /$ ha, tekoči lesni prirastek pa $4,9 \mathrm{~m}^{3} / \mathrm{ha}$. V letu 1996 so te vrednosti po podatkih Zavoda za gozdove Slovenije narasle na $211 \mathrm{~m} 3 / \mathrm{ha}$ oziroma 5,5 $\mathrm{m}^{3} /$ ha (Ferlin, 1998). V Sloveniji je bila leta 1996 skupna lesna zaloga 231 milijonov $\mathrm{m}^{3}$ (Pogačnik, 1998). Po vzorčno zasnovanih ugotovitvah Hočevarja (1998) znaša lesna zaloga slovenskega gozda celo $272 \mathrm{~m}^{3} /$ ha, prirastek lesne zaloge pa $6,4 \mathrm{~m}^{3} /$ ha.

Slovenija ima v primerjavi z drugimi evropskimi državami zelo visoko lesno zalogo na enoto površine. Nizko lesno zalogo na enoto površine $\left(50-100 \mathrm{~m}^{3} / \mathrm{ha}\right)$ imajo mediteranske in skandinavske države.

\section{Ohranjanje kakovosti gozda}

Slovenski gozdovi so po stopnji poškodovanosti v srednjeevropskem povprečju, poškodovanost dreves pa je kljub nekaterim izboljšavam velika. Kljub zmanjšanju 
ekološke stabilnosti gozdov zaradi naravnih motenj je delež poškodovanega (preostalega) drevja in gozda v zadnjih letih stabilen $(18-19 \%)$ in nižji kot pred letom 1990 (Preglednica 2). Občutno se je namreč zmanjšal delež poškodovanih iglavcev (od 43 na $27 \%$ ), čeprav se je pri listavcih povečal na $13 \%$. Glavni razlogi so najverjetneje $\mathrm{v}$ ugodnejših klimatskih pogojih za rast iglavcev ter $\mathrm{v}$ zmanjševanju emisij po letu 1987 (Ferlin, 1998).

Ogroženost najobilnejšega slovenskega obnovljivega vira zahteva po mnenju Bogatajeve (1997) upoštevanje njegove dolgoročnosti, izjemne prepletenosti odnosov, ki jih z nepremišljenimi, v kratkoročne potrebe usmerjenimi posegi, lahko nepovratno prizadenemo.

Preglednica 2: Indeks osutosti drevja Slovenije (nad $25 \%$ osutost) v obdobju 1987-1996

\begin{tabular}{|l|c|c|c|c|c|c|}
\hline $\begin{array}{l}\text { Drevesne } \\
\text { vrste }\end{array}$ & $\mathbf{1 9 8 7}$ & $\mathbf{1 9 8 9}$ & $\mathbf{1 9 9 1}$ & $\mathbf{1 9 9 3}$ & $\mathbf{1 9 9 5}$ & $\mathbf{1 9 9 6}$ \\
\hline Iglavci & $43 \%$ & $39 \%$ & $31 \%$ & $31 \%$ & $26 \%$ & $27 \%$ \\
\hline Listavci & $9 \%$ & $8 \%$ & $6 \%$ & $8 \%$ & $15 \%$ & $13 \%$ \\
\hline Skupaj & $24 \%$ & $23 \%$ & $16 \%$ & $18 \%$ & $22 \%$ & $19 \%$ \\
\hline
\end{tabular}

Vir: Bogataj, 1997; Ferlin, 1998

\section{ZAŠČITA BIOTSKE RAZNOVRSTNOSTI (CILJ 15)}

Vzrok za izjemno biotsko pestrost Slovenije je po mnenju Skoberneta (1996) in Mršića (1997) velika raznovrstnost in kompleksnost abiotskih in biotskih dejavnikov, zlasti preplet vplivov štirih biogeografskih sistemov-Alp, Dinaridov, Sredozemlja in Panonske nižine, geomorfološka in litološka razgibanost površja ter svojstven tektonski razvoj slovenskega ozemlja.

Narava je relativno ohranjena, vendar ogroženost nekaterih živalskih vrst opozarja na njeno ogroženost: ogroženih je $12 \%$ višjih rastlin, $36 \%$ listnatih mahov, $56 \%$ vretenčarjev (Vidic, 1996; Skoberne 1996). Na rdeči seznam ogroženih praprotnic in semenk Slovenije je uvrščenih 29 (30) rastlin, po današnjem vedenju je štetih za izumrle 24 rastlinskih vrst, prizadetih pa je 40. V Sloveniji je iztrebljeno 24 vrst cvetnic in 19 vrst vretenčarjev (Drobne, Martinčič, 1997). Ker so v Sloveniji zaradi uveljavljanja prebiralne sečnje kakovostni in sklenjeni gozdovi, se nam (še) ni treba ubadati z izumiranjem gozdnih vrst (Kryštufek, 1998). Gledano v celoti pa je zaradi posegov v naravo živi svet Slovenije vse bolj ogrožen (Skoberne, 1996, s. 47).

Temeljni pogoj za ohranjanje biotske raznovrstnosti je ohranjanje raznovrstnosti ekosistemov in naravnega okolja ter ohranjanje in reševanje dovolj velikih populacij vrst za preživetje v njihovem naravnem okolju (Mršić, 1997, s. 13). V Sloveniji je zavarovanega manj kot $8 \%$ njenega ozemlja (povprečje držav EZ - $11 \%$ ), od tega večji del (4\% ozemlja Slovenije) obsega območje Triglavskega narodnega parka 
$\left(84,8 \mathrm{~km}^{2}\right)$ (Vidic, 1996). Po mnenju Berginca (1996, s. 15) se Slovenija s sedanjim deležem zavarovanih območij narave $v$ Evropi uvršča med manj urejene države na tem področju. V obdobju po podpisu Agende 21 je delež zavarovanih območij praktično ostal nespremenjen.

\section{ZAŠČITA VIROV SVEŽE VODE (CILJ 18)}

\section{Količine sveže vode}

Slovenija je bogata z vodo, saj jo označuje velik odtok iz lastnega ozemlja ter hkrati večje količine prispele rečne vode iz sosednje Avstrije. Skupaj se preko ozemlja Slovenije pretoči na leto približno $32 \mathrm{~km}^{3}$ vode oziroma 32 milijard $\mathrm{m}^{3}$ na leto (Kolbezen, 1998). Odtok vode iz ozemlja Slovenije je sicer približno trikrat nad svetovnim povprečjem, vendar je hkrati gostota prebivalstva v Sloveniji približno 2,5krat nad svetovnim povprečjem (41 prebivalcev na $\mathrm{km}^{2}$ ).

V Sloveniji znašajo letne interne rečne vode 18,7 milijard m3 oziroma okoli $9400 \mathrm{~m} 3$ na prebivalca letno. Količina internih rečnih vod na prebivalca je v Sloveniji nekaj nad svetovnim in bistveno nad evropskim povprečjem. Ob upoštevanju vseh rečnih vod, ki se pretakajo po ozemlju Slovenije (zlasti dotok rečne vode iz ozemlja Avstrije), pa je na prebivalca letno na razpolago $16000 \mathrm{~m}^{3}$ skupne rečne vode.

Po oceni je v Sloveniji celotna letna načrpana voda (osebna, komunalna, energetskahladilne vode, kmetijska in druga gospodarska) okoli $600 \mathrm{~m}^{3}$ na prebivalca oziroma 16441 na prebivalca dnevno (Lah, 1998). Po tej oceni načrpa Slovenija več kot 1 milijardo $\mathrm{m}^{3}$ vode na leto, kar predstavlja $5 \%$ internih rečnih vod in $3 \%$ vseh rečnih vod, ki prečkajo ozemlje naše države. Brez upoštevanje hladilnih voda za proizvodnjo električne energije pa črpamo okoli $2 \%$ internih rečnih vod, kar je bistveno pod evropskim in svetovnim povprečjem. V javne vodovode je na leto načrpano (podtalnica, izviri, le nekaj odstotkov iz površinskih vodnih virov) okoli 266 milijonov $\mathrm{m}^{3}$ vode oziroma $1,4 \%$ internih rečnih vod. Od tega je zagotovljenih oziroma prodanih 155 milijonov $\mathrm{m}^{3}$, razlike med načrpano in prodano vodo predstavljajo izgube, ki znašajo okoli $41 \%$ (okoli 111 milijonov $\mathrm{m}^{3}$ letno). Velike izgube so ena od možnih rezerv za oskrbo prebivalstva, saj jih lahko zmanjšamo vsaj na največ $25 \%$.

\section{Kakovost sveže vode}

Slovenija je torej s svežo vodo bogata evropska država, vendar so njene reke zmerno do močno onesnažene, zato za oskrbo s pitno vodo niso primerne brez zahtevnih postopkov čiščenja. V obdobju po podpisu deklaracije v Riu se je kakovost površinskih voda $\mathrm{v}$ Sloveniji nekoliko izboljšala, zlasti zaradi zmanjšanja količin industrijskih odpadnih voda. Za oskrbo prebivalstva in dejavnosti s pitno vodo se 
rečna voda uporablja le izjemoma, pomembni so kraški izviri in talna voda. Čeprav poraba vode $\mathrm{v}$ zadnjih letih stagnira ali celo rahlo upada, se je kakovost vodno oskrbno pomembnih kraških izvirov in območij črpanja talne vode $\mathrm{v}$ zadnjih letih nekoliko poslabšala (Plut, 1998). Vendar analize rečne vode za leto 1995 in 1996 kažejo, da se je tudi kakovost površinskih vodotokov in sanitarna kakovost morja ponovno nekoliko poslabšala (Okolje v Sloveniji..., 1998, s. 102, 103). Opozoriti velja na dejstvo, da so številne slovenske reke onesnažene že več desetletij, izrazita je kratkotrajna, a močna poletna onesnaženost (Radinja, 1979a; Plut, 1998). Radinja (1979b, s. 76) je pred dvema desetletjema opozoril na absurdno stanje, da je kljub izredni namočenosti Slovenije in njenega alpskega sveta ponekod zmanjkovalo čiste vode.

V Avstriji je bilo leta $199590 \%$ prebivalcev priključenih na kanalizacijsko omrežje, v Sloveniji pa le $44 \%$ (brez upoštevanja greznic); $70 \%$ avstrijskih prebivalcev je bilo priključenih na čistilne naprave za vode, v Sloveniji pa 20 - 30\% (različne strokovne ocene). V začetku devetdesetih let je Avstrija biološko in/ali kemično učinkovito čistila dve tretjini odpadnih vod, Slovenija pa le desetino. Leta 1992 se je je slaba desetina avstrijskih rečnih odsekov uvrščala med močno ali zelo močno onesnažene, $v$ Sloveniji pa četrina le - teh. Nacionalni program varstva okolja (1998) uvršča izboljšanje kakovosti voda med tri temeljne vsebinske okoljske prioritete (ob ohranjanju biotske raznovrstnosti in gospodarjenju z odpadki) Slovenije.

\section{SLOVENIJA, GEOGRAFSKO OKOLJE IN NADALJNJE NALOGE URESNIČEVANJA AGENDE 21}

Snovno - energetski antropogeni tokovi, širjenje pozidanih površin, zračne emisije in odpadne vode obremenjujejo geografsko okolje Slovenije in seveda v manjši meri vplivajo tudi na planetarni ekosistem. Glede na svetovno povprečje prebivalec Slovenije nadpovprečno obremenjuje planetarni ekosistem. Slovenija se uvršča med zmerno onesnažene evropske države, a z močno onesnaženimi dolinsko - kotlinskimi sistemi in z veliko porabo naravnih virov na prebivalca. Onesnaževanje geografskega okolja se je zlasti v urbanih ekosistemih in njihovem obrobju krepilo vse do srede 80 . let, nato pa so prisotni tako procesi zmanjševanja kot povečevanja pokrajinskega obremenjevanja (Špes, 1998). Odprava oziroma zmanjševanje onesnaževanja, ne pa prestavljanje virov onesnaževanja, je edini učinkoviti sanacijski ukrep (Radinja, 1979b, s. 76).

Slovenija je sredi 90 . let prispevala na prebivalca $\mathrm{k}$ globalnemu onesnaževanju nadpovprečni delež $\mathrm{k}$ zračnemu in vodnemu onesnaževanju, $\mathrm{v}$ primerjavi z nekaterimi evropskimi državami pa zmeren, povprečen delež. Velike količine vodnih virov in gozdnih površina na prebivalca, povečevanje gozdnih površin, so na eni strani kazalci večje razpoložljivosti obnovljivih naravnih virov, na druga pa tudi posredni kazalec večjih samočistilnih zmogljivosti okolja. Okoli 0,1 ha njivskih površin na prebivalca 
pa je kazalec omejenih možnosti prehranske samooskrbe in hkrati dejanskih ter možnih kmetijskih pritiskov na njivske ekosisteme. V primerjavi z drugimi izbranimi evropskimi državami je delež prebivalcev Slovenije, priključenih na čistilne naprave (kazalec okoljske odzivnosti države), zelo skromen.

Ocena uresničevanja izbranih ciljev Agende 21 v Sloveniji kaže, da Slovenija večino sprejetih in moralno (ne pa zakonsko) obvezujočih ciljev še ne uresničuje ali delno uresničuje in zaostaja za povprečjem držav EZ, ki pa tudi niso $v$ celoti uspešne pri uresničevanju mednarodnih okoljskih obveznosti. V prihodnjih dveh desetletjih bodo $\mathrm{z}$ vidika Agende 21 razen problematike zmanjševanja snovno energijske porabe (in odpadkov) temeljne naloge globalizacijske okoljske naloge Slovenije:

1. zmanjšanje emisij toplogrednih plinov, zlasti ogljikovega dioksida;

2. zmanjšanje emisij prometa (dušikovih oksidov), ki tudi prekomejno onesnažujejo ozračje;

3. izboljšanje kakovosti rek, ki zapuščajo ozemlje Slovenije (zlasti Soča, Sava, Kolpa, Drava, Mura).

4. ohranjanje biotske raznovrstnosti (povečanje zavarovanih območij, zmanjšanje pritiskov izven zavarovanih območij).

\section{LITERATURA}

- Agenda 21: Programme of Action for Sustainable Development, 1992: United Nations, New York.

- Berginc M., 1996: Naravni parki v Sloveniji, V:Vrt Evrope-parki za življenje v Sloveniji, str. 15-24, Ljubljana.

- Bogataj N., 1997: Degradacija gozda s posebnim ozirom na metodološko problematiko popisa (magistrsko delo), Oddelek za geografijo Filozofske fakultete, Ljubljana.

- Drobne D., Martinčič A., 1997: Odločitev o okolju-odločitev o življenju, V: Kemizacija okolja in življenja-do katere meje? str. 32-41, Ljubljana.

- Environment in the European Union at the Turn of the Century, 1999: European Environment Agency, Copenhagen.

- Europe's Environment, 1995: European Environmental Agency, Copenhagen.

- Ferlin F., 1998: Uspešnost novega sistema sonaravnega gospodarjenja z gozdovi v Sloveniji, V: Gozdarski vestnik 56, str. 81-96, Ljubljana.

- Hočevar M., 1998: Možnosti in zanesljivost ocene lesne zaloge in prirastka na podlagi popisa propadanja gozdov 1995, V: Zbornik gozdarstva in lesarstva 52, str. 93-118, Ljubljana.

- Kladnik D., Gabrovec M., 1998: Raba tal, V: Geografski atlas Slovenije, str.180182, Ljubljana. 
- Indicators of Sustainable Development - A Pilot Study Following the Methodology of the UN Commission on Sustainable Development, 1997: Eurostat, Luxembourg.

- Indicators of Sustainable Development - Framework and Methodologies, 1996: UN Commission on Sustainable Development, United Nations, New York.

- Kolbezen M., 1998, Hidrologija, V: Geografija Slovenije, str139-172, Ljubljana.

- Kryštufek B., 1998: Zagotavljanje biotske pestrosti in raba naravnih virov, V: Naprej k naravi, str. 113-128, Ljubljana.

- Lah A., 1998: Varstvo naravne dediščine, V: Geografija Slovenije, str. 471-489, Ljubljana.

- Mršić N., 1997: Biotska raznolikost Slovenije, Slovenija-“vroča točka“ Evrope, Ministrstvo za okolje in prostor, Ljubljana.

- Nacionalni program varstva okolja, 1998: Ministrstvo za okolje in prostor RS, Ljubljana.

- $\quad$ Okolje v Sloveniji 1996, 1998: Ministrstvo za okolje in prostor RS, Ljubljana.

- Plut D.,1998: Varstvo geografskega okolja, Oddelek za geografijo Filozofske fakultete, Ljubljana.

- Pogačnik N., 1998: Nekatere značilnosti gozdov in gozdarstva v Evropski uniji, V: Gozdarski vestnik 56, str. 97-103, Ljubljana.

- Radinja D., 1979a: Onesnaženost slovenskih rek in njene pokrajinske značilnosti, V: Geografski vestnik 51, str. 75-84, Ljubljana.

- Radinja D., 1979b: Pokrajinske razsežnosti in značilnosti industrializacijske onesnaženosti v Sloveniji, V: Geographica Slovenica 9, str.75-83, Ljubljana.

- $\quad$ Skoberne P., 1996: Stanje slovenske narave, V: Zbornik posvetovanja, Uprava za varstvo narave, str. 46-58, Ljubljana.

- S Špes M., 1998: Onesnaženost in onesnaževanje ozračja in vod, V: Geografski atlas Slovenije, str. 320-322, Ljubljana.

- Vidic J., 1996: Naravne vrednote zunaj zavarovanih območij, V: Varstvo narave zunaj zavarovanih območij, Urad RS za prostorsko planiranje, str. 197-202, Ljubljana.

\section{PROTECTION OF GEOGRAPHIC ENVIRONMENT IN THE PERIOD OF GLOBALIZATION - SLOVENIA AND AGENDA 21}

\section{Summary}

Agenda 21 was signed in Rio de Janeiro in June 1992 also by Slovenia. With such act Slovenia took the responsibility to execute the economic progress with preservation of planetary ecosystem and as well to improve the condition of environment on its territory. By means of some environmental indicators of sustainable development (protection of air, forests, water and preservation of biotic variety) we were establishing if Slovenia is following the basic environmental aims of Agenda 21. 
In the middle nineties Slovenia contributed per inhabitant over-average share to global air and water pollution, however compared with some European countries the said share was moderate, average. Total gas emissions of hotbed increased in the years following the adoption of Agenda 21 (1992-1996), in year 1995 they were represented by app. 21 millions of tons in $\mathrm{CO}_{2}$ equivalents or by 10,7 tons per inhabitant, only emission of $\mathrm{CO}_{2}$ by 7,9 tons per inhabitant. In contrast to emissions of $\mathrm{SO}_{2}$ yearly emissions of $\mathrm{NO}_{\mathrm{x}}$ were increasing in the period 1992-1996, due to the increased concentration of traffic with motor vehicles. In year 1996 emissions of $\mathrm{NO}_{\mathrm{X}}$ amounted to 70.000 tons or $35,2 \mathrm{~kg} \mathrm{NO}_{\mathrm{x}}$ per inhabitant. Road traffic contributed with nearly two thirds to all emissions of $\mathrm{NO}_{\mathrm{x}}$.

Great amounts of internal river water per inhabitant $\left(9400 \mathrm{~m}^{3}\right)$ and increase of forest areas per inhabitant $(0,56 \mathrm{ha})$ indicate on one side that great amounts of natural sources, which could be revived, are available, and on the other side they indicate indirectly on bigger self-cleaning capabilities of environment. But merely 0,1 ha of field areas per inhabitant represent an indicator of limited possibilities for self-supply with food and furthermore of actual and possible rural pressures on field ecosystems.

Usage of water decreased somewhat around year 1990 due to the decrease of industry but it stabilized in general. Quality of fresh water sources indicate slight improvement of river water and worsening of quality of ground water as well as of water from karst sources. In comparison with other selected European countries share of inhabitants of Slovenia (app. 20-30\%), connected to the cleaning devices (indicator of environmental response of the country), is ranging pretty low.

The share of territory of Slovenia which is being protected, amounts to less than $8 \%$ (in countries of European Unit over 11\%), from which most part (4\% of the territory of Slovenia) is being occupied by the only Slovene natural park - Triglav natural park $\left(84,8 \mathrm{~km}^{2}\right)$. Share of protected areas is not increasing, however pressures on biotic variety are increasing due to building of highways, blind suburbanization, tourism and rural pressures (intensity of food production.)

Estimation of realization of selected aims of Agenda 21 in Slovenia indicates that most of adopted aims are not being realized yet in Slovenia and that Slovenia is falling behind the countries of European Unit. Regarding Agenda 21 in the following two decades the following basic environmental tasks will have been set for Slovenia:

1. decrease of emission of hotbed gasses, especially of carbon dioxide;

2. decrease of traffic emissions (nitric oxide) which are also excessively polluting the air;

3. improvement of quality of rivers which run out of the territory of Slovenia (especially Soča, Sava, Kolpa, Drava, Mura);

4. preservation of biotic variety (increase of protected areas, decrease of pressures outside the protected areas). 